Supplementary Information

\title{
Unraveling self-carried chemical feedback on assembly processes and the self-termination of growth in $\mathrm{Au}(\mathrm{I})$-thiolate lamellae
}

Chuying Dai, ${ }^{1 \#}$ Shujue Xu, ${ }^{1 \#}$ Yang Yu, ${ }^{1}$ Minjie Li, ${ }^{* 1}$ and Sean Xiao-An Zhang ${ }^{1}$

1 State Key Laboratory of Supramolecular Structure and Materials, College of Chemistry, Jilin

University, Changchun, 130012, P. R. China.

Fax: +86-431-85153812

E-mail: liminjie@jlu.edu.cn 


\section{Supplementary Data}

(a)

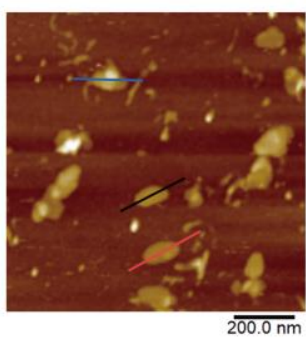

(b)

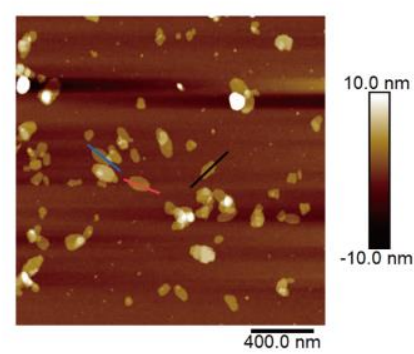

(c)

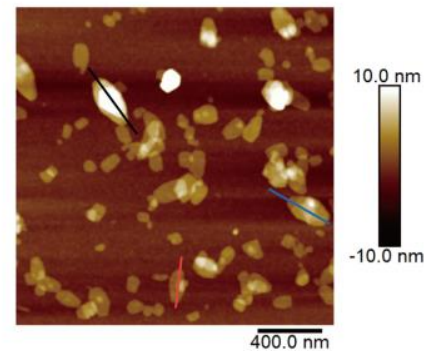

(d)

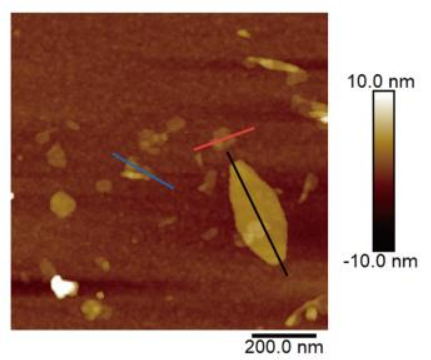

(e)

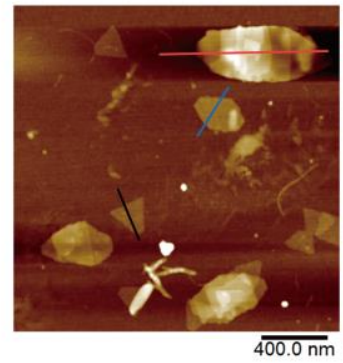

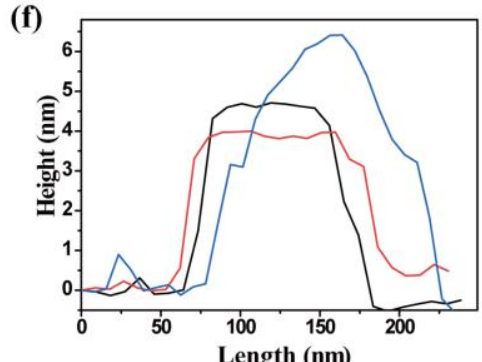

(g)
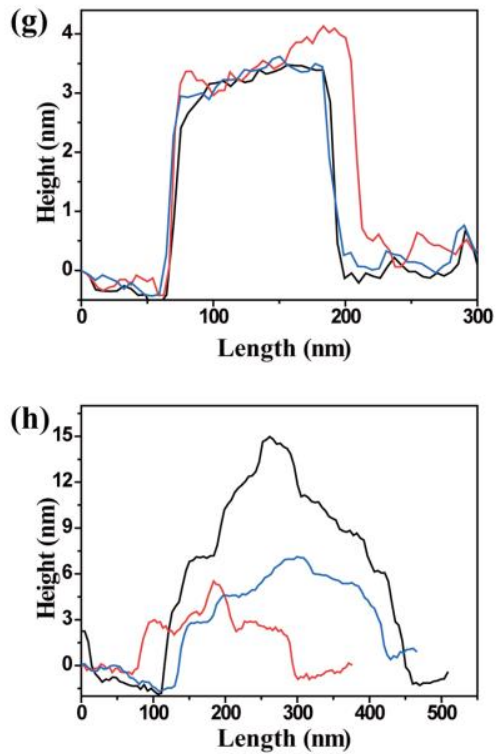

(i)
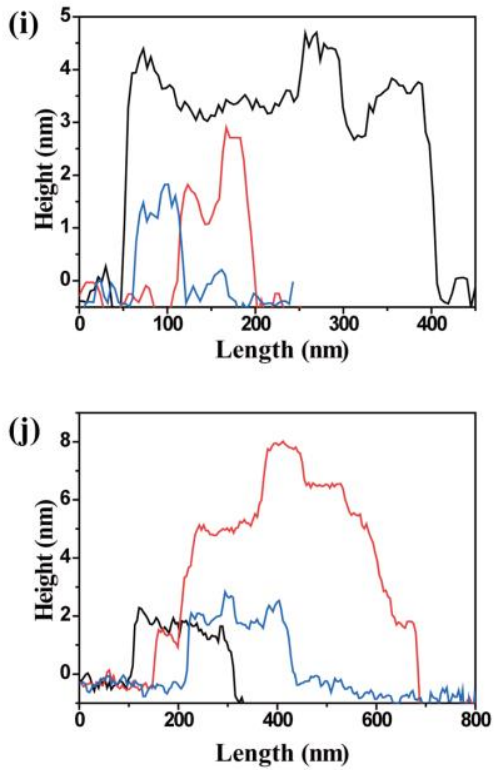

Supplementary Figure 1. (a-e)AFM images and (f-j) height analysis of P1-P5. AFM height analyses suggest that larger lamellae tends to have thicker thickness. 

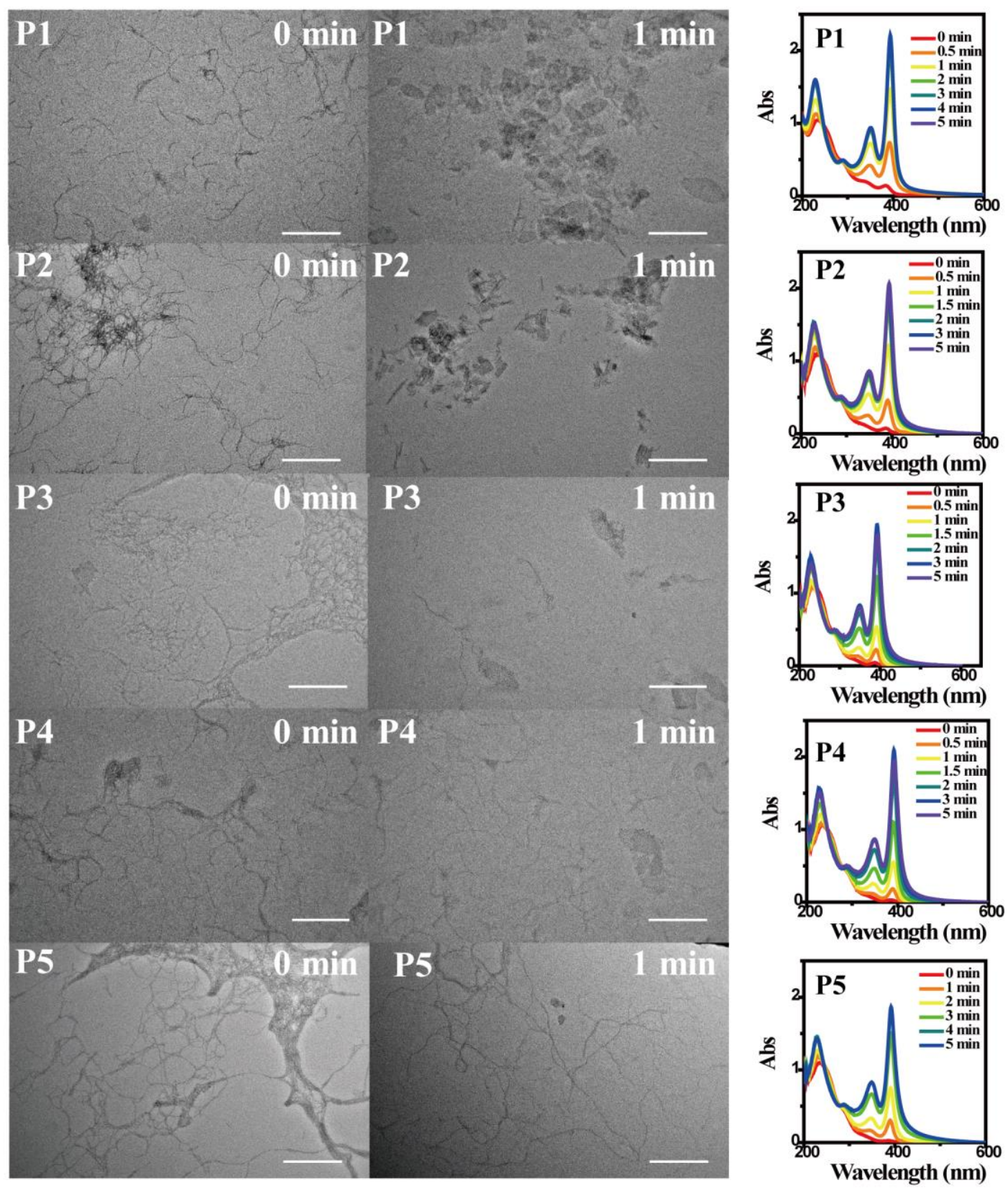

Supplementary Figure 2. TEM images of P1-P5 assembled at $0 \mathrm{~min}$ and $1 \mathrm{~min}$, respectively, and the UV-vis absorption spectral change of P1-P5 with time. Scale bar $=200 \mathrm{~nm}$. From the TEM images, it can be seen that the size of strings assembled at 0 min for P5 is much larger than P1. The transformation of the strings to lamellae at $1 \mathrm{~min}$ become less and less from P1to $\mathrm{P} 5$, which is in consistent with the UV-Vis spectral change. There are still strings for P4 and P5 at 1 min, which are better dispersed, it can be clearly seen that the string for P5 is longer than P4. So we deduce that the strings is larger and larger from P1 to P5. Samples at $0 \mathrm{~min}$ means they were cooled immediately after mixing of the reactants. 
(a)

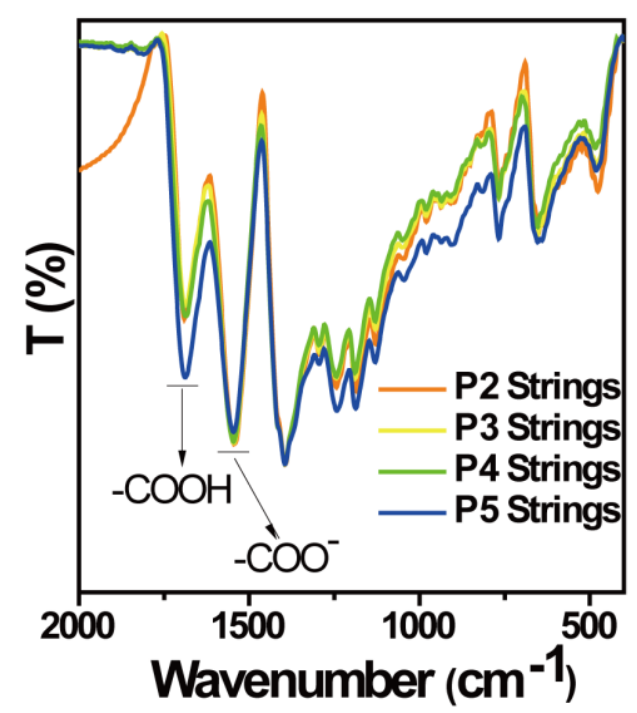

(b)

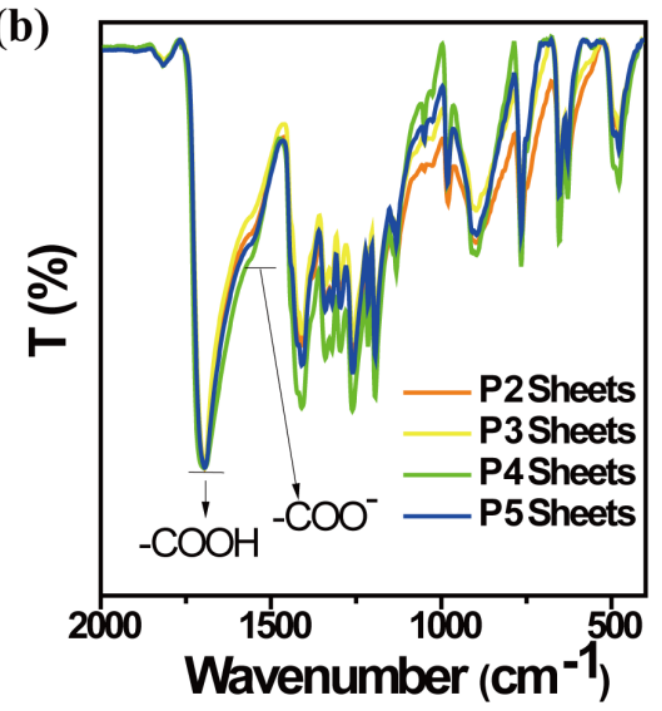

Supplementary Figure 3. IR spectra of the (a) strings and (b) lamellae for P2-P5. 

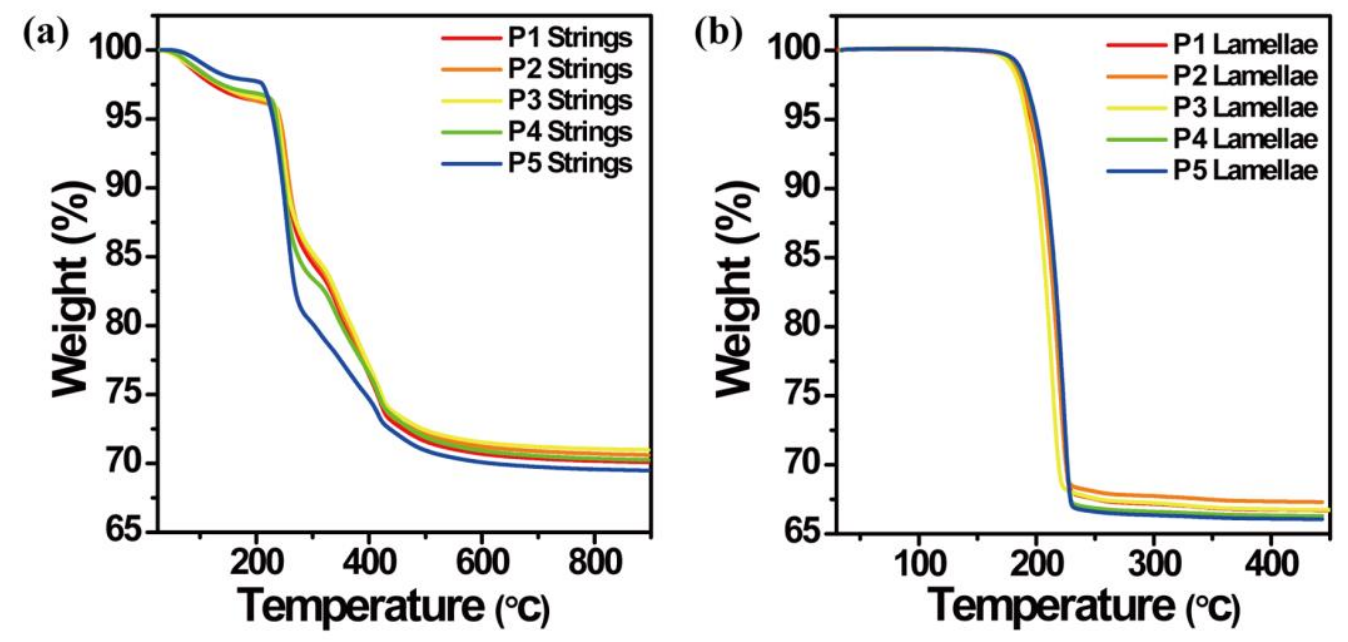

Supplementary Figure 4. TGA of the (a) strings and (b) lamellae for P1-P5. 
(a)

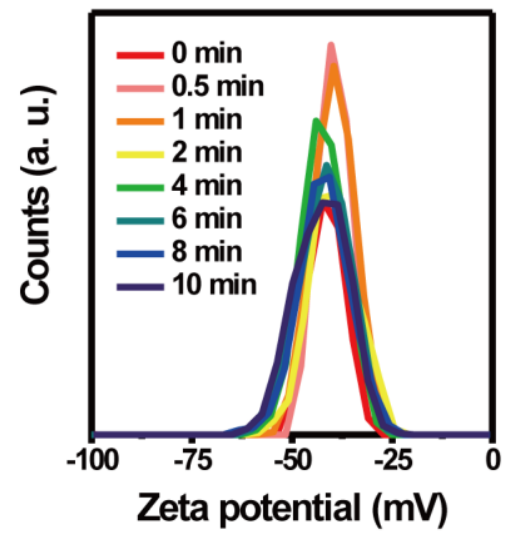

(c)

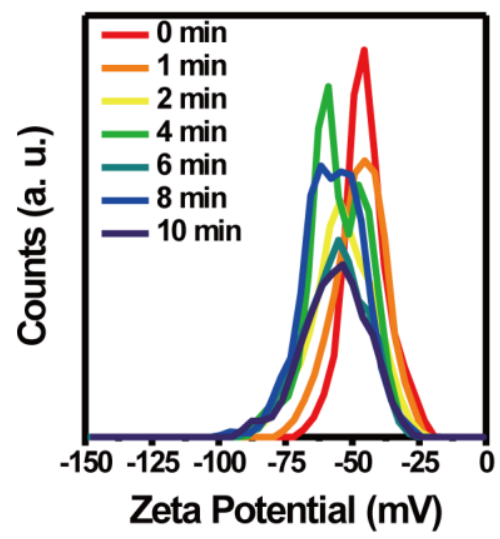

(e)

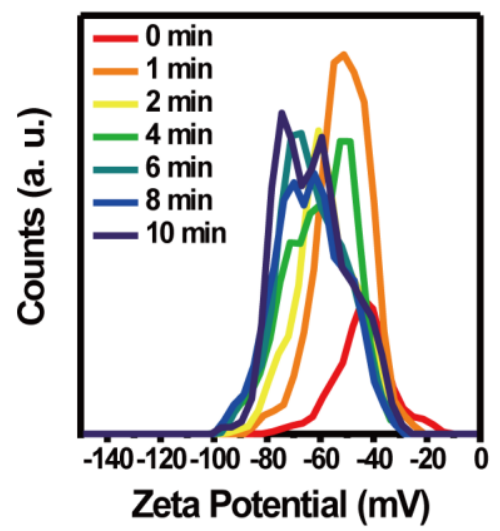

(b)

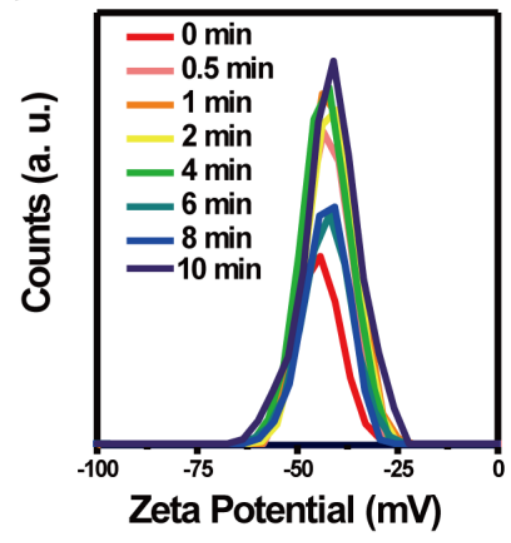

(d)

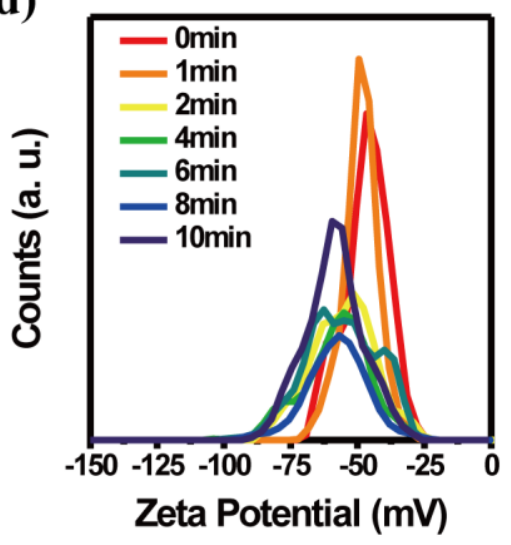

Supplementary Figure 5. Changes of zeta-potential with assembly time for P1-P5 (a-e).

Samples at 0 min means they were cooled immediately after mixing of the reactants. 

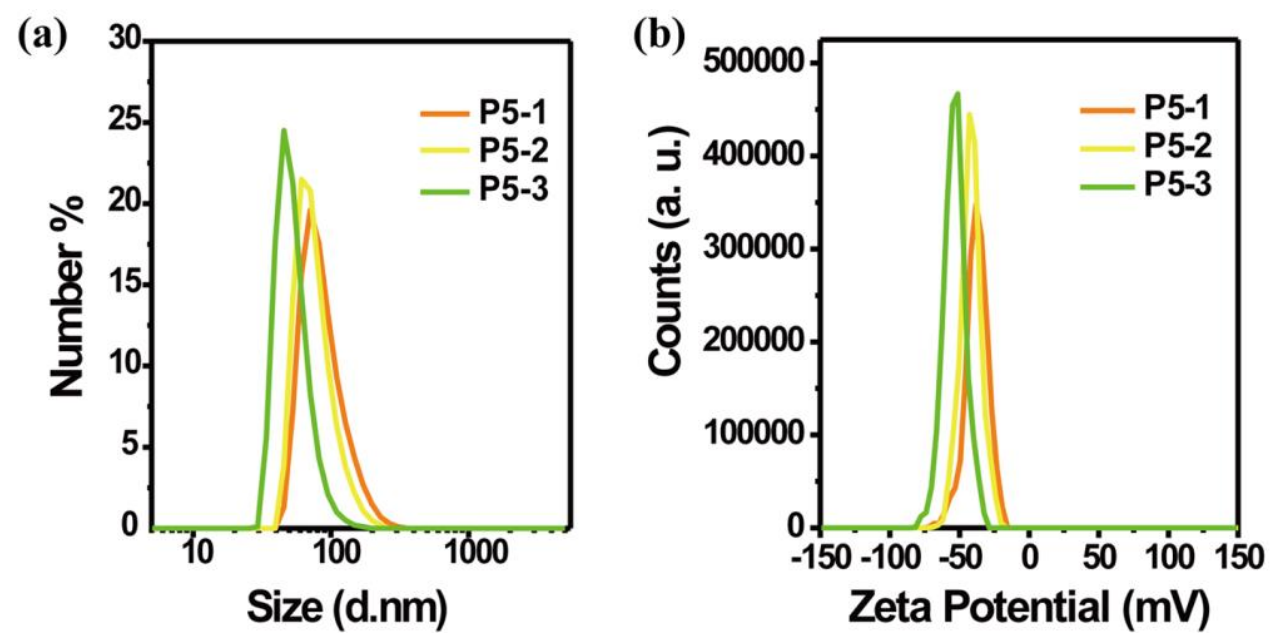

Supplementary Figure 6. (a) DLS and (b) Zeta potential of P5-1, P5-2, P5-3. 


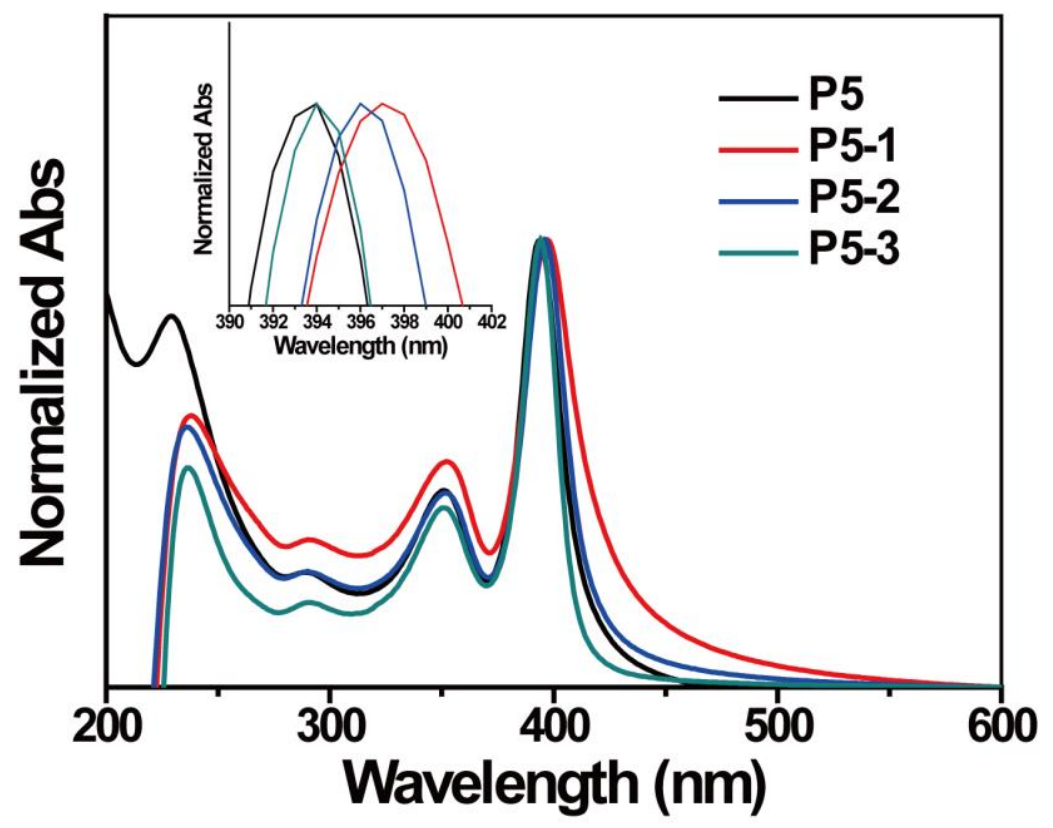

Supplementary Figure 7. Normalized UV-Vis absorption spectra of P5, P5-1, P5-2 and P5-3. Inset: the enlarged spectra. 


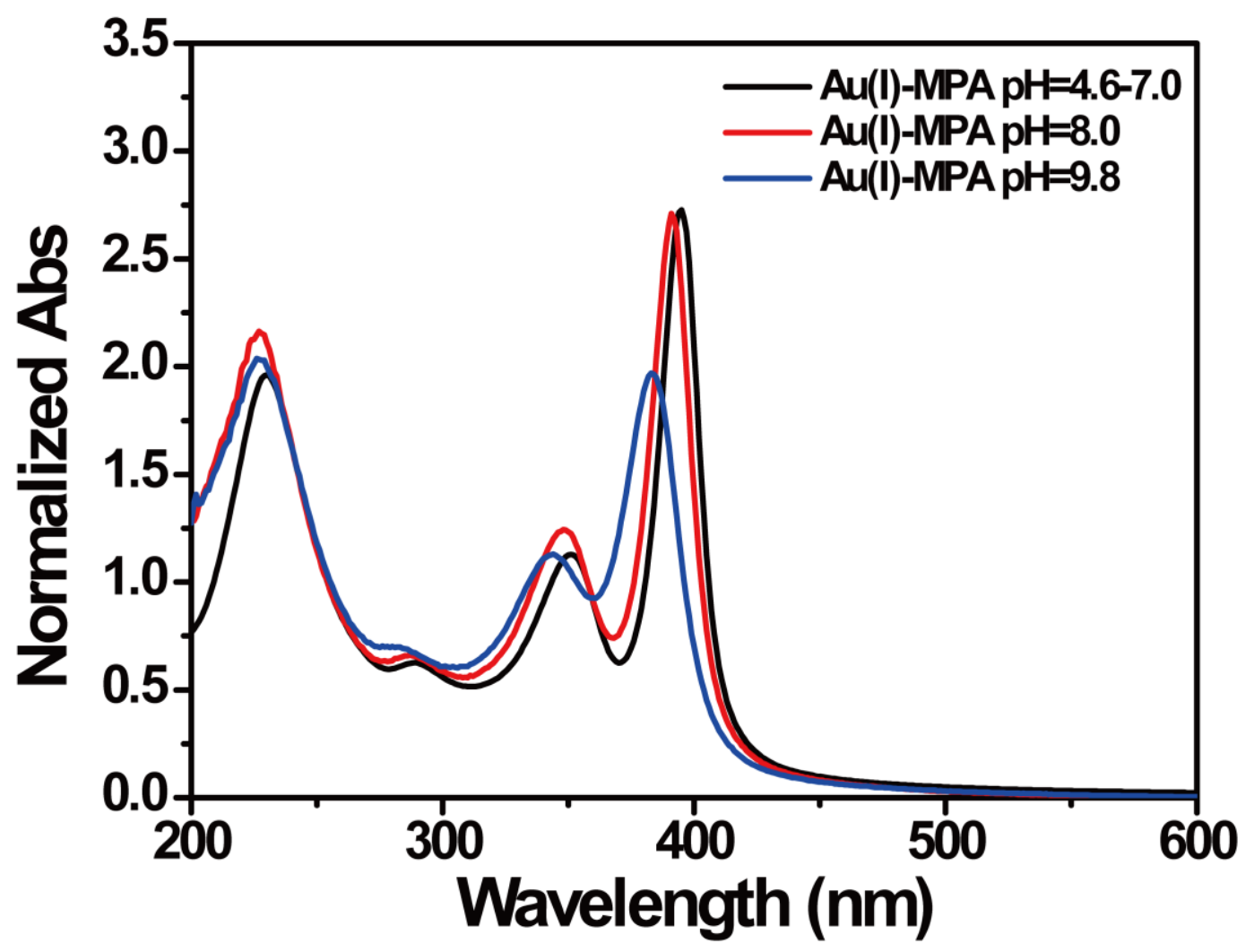

Supplementary Figure 8. UV-Vis absorption spectra of $\mathrm{P} 1$ at different $\mathrm{pH}$ values, the sheets begin to disassemble at $\mathrm{pH}=9.8$, resulting in the blue-shift and decline of absorption. 
(a)

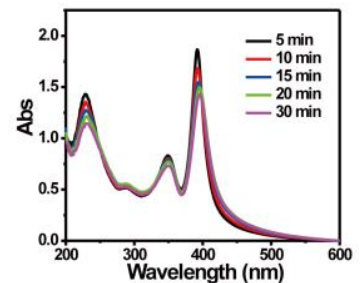

(b)

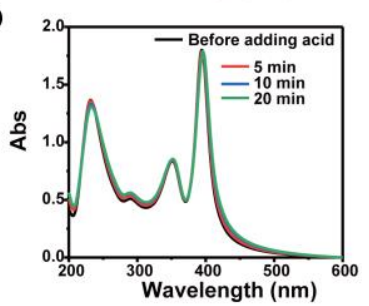

(c)

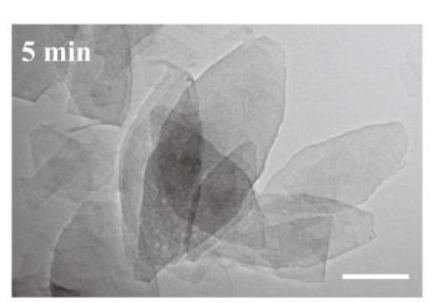

(e)

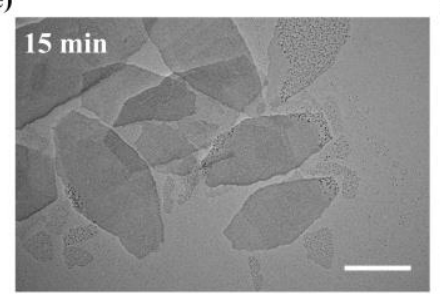

(d)

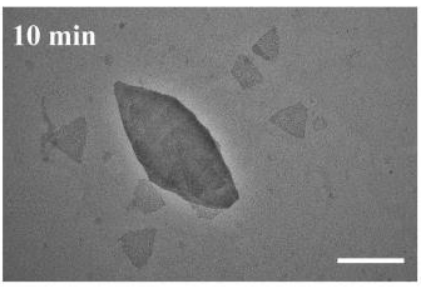

(f)

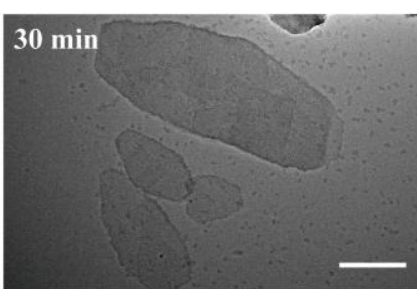

Supplementary Figure 9. (a) UV-Vis absorption spectra and (c-f) TEM images of P5 heated for different periods of time of $5 \mathrm{~min}, 10 \mathrm{~min}, 15 \mathrm{~min}$ and $30 \mathrm{~min}$. Scale bar=200 $\mathrm{nm}$. (b) UV-Vis absorption spectra of P5 before and after adding acid to tune the $\mathrm{pH}$ to 4.63 and allowed to boil for another 20 minutes, and there is not obvious decline of absorption, indicating no decomposition of the sheets has happened. 


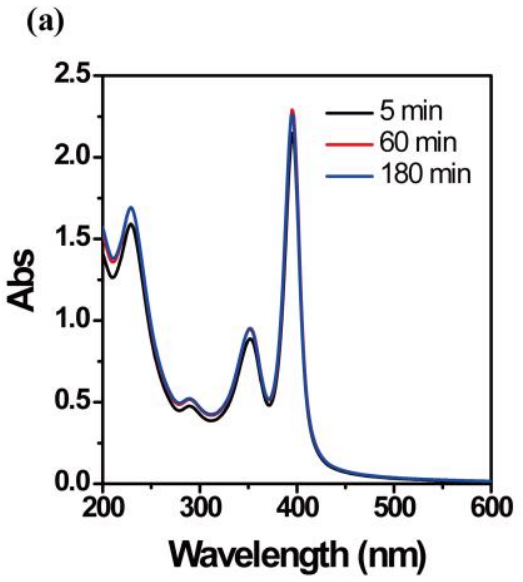

(b)

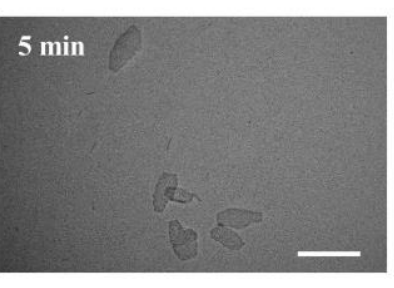

(d)

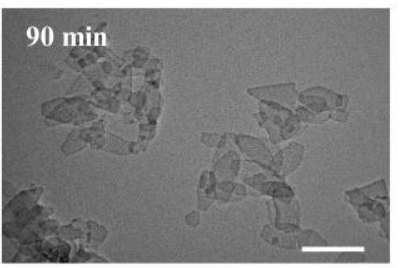

(c)

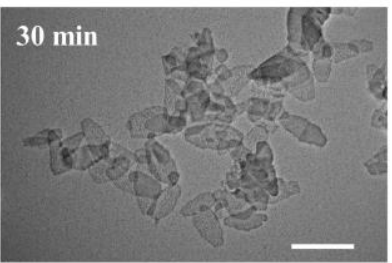

(e)

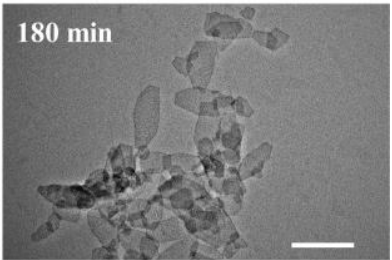

Supplementary Figure 10. (a) UV-Vis absorption spectra and (b)TEM images of P1 assembled for different periods of time. Scale bar=200 nm. 


\section{Supplementary Tables}

Supplementary Table 1. $\mathrm{pH}$ values of $\mathrm{HAuCl}_{4}$ and MPA-Na after mixed with different amount of $\mathrm{NaOH}$.

\begin{tabular}{cccc}
\hline Name & pH values & Name & pH values \\
\hline $\mathrm{HAuCl}_{4}+0 \% \mathrm{NaOH}$ & 3.10 & $\mathrm{MPA}-\mathrm{Na}+100 \% \mathrm{NaOH}$ & 10.32 \\
\hline $\mathrm{HAuCl}_{4}+33 \% \mathrm{NaOH}$ & 3.99 & $\mathrm{MPA}-\mathrm{Na}+67 \% \mathrm{NaOH}$ & 9.97 \\
\hline $\mathrm{HAuCl}_{4}+67 \% \mathrm{NaOH}$ & 5.38 & $\mathrm{MPA}-\mathrm{Na}+33 \% \mathrm{NaOH}$ & 9.53 \\
\hline $\mathrm{HAuCl}_{4}+82 \% \mathrm{NaOH}$ & 6.04 & $\mathrm{MPA}-\mathrm{Na}+18 \% \mathrm{NaOH}$ & 6.43 \\
\hline $\mathrm{HAuCl}_{4}+100 \% \mathrm{NaOH}$ & 6.59 & $\mathrm{MPA}-\mathrm{Na}+0 \% \mathrm{NaOH}$ & 5.12 \\
\hline
\end{tabular}


Supplementary Table 2. $\mathrm{pH}$ value changes of P1-P5 assembled at $0 \mathrm{~min}$ (represent for samples were cooled immediately after mixing of the reactants) and 5 min.

\begin{tabular}{ccc}
\hline Name & pH values & $\mathrm{pH}$ values \\
& 0 min (strings) & $5 \min$ (sheets) \\
\hline P1 & 5.24 & 5.65 \\
P2 & 5.23 & 5.69 \\
P3 & 5.25 & 5.85 \\
P4 & 5.25 & 5.98 \\
P5 & 5.23 & 5.99 \\
\hline
\end{tabular}

